\title{
CAPTURE AND USE OF COAL MINE VENTILATION AIR METHANE
}

Semi-Annual Technical Progress Report

April 1, 2003 through September 30, 2003

Deborah A. Kosmack

Report Issued: October 2003

DOE Cooperative Agreement DE-FC26-02NT41620

䎡 CONSOL ENERGY

CONSOL Energy Inc.

Research \& Development

4000 Brownsville Road

South Park, PA 15129 


\section{DISCLAIMER}

This report was prepared as an account of work sponsored by an agency of the United States Government. Neither the United States Government nor any agency thereof, nor any of their employees, makes any warranty, express or implied, or assumes any legal liability or responsibility for the accuracy, completeness, or usefulness of any information, apparatus, product, or process disclosed, or represents that its use would not infringe privately owned rights. Reference herein to any specific commercial product, process, or service by trade name, trademark, manufacturer, or otherwise does not necessarily constitute or imply its endorsement, recommendation, or favoring by the United States Government or any agency thereof. The views and opinions of authors expressed herein do not necessarily state or reflect those of the United States Government or any agency thereof. 


\begin{abstract}
This is the second semi-annual Technical Progress report under the subject agreement. During the second six months of the project the following items were accomplished: 1) the detailed engineering design was started by MEGTEC Systems, 2) a pre-investigation meeting was held with Mine Safety and Health Administration (MSHA) to discuss the allegations in the 101(c) Petition for Modification of Application of Mandatory Safety Standard, 3) the 101(c) Petition for Modification was withdrawn, although negotiations continue with MSHA, and 4) detailed engineering was started by CONSOL Energy. These aspects of the project, as well as progress on public communications are discussed in detail in this report.
\end{abstract}




\section{TABLE OF CONTENTS}

Disclaimer

Abstract

Introduction

Experimental

Results and Discussion

Conclusion

References

$\underline{\text { Page }}$

i

ii

2

3

3

\section{ATTACHMENTS}

Attachment

A Paper Presented at Conferences $\underline{\text { Page }}$

A-1 


\section{INTRODUCTION}

Methane is the second most important non-water greenhouse gas (GHG). Coal mining, and particularly coal mine ventilation air, is a major source of anthropogenic methane emissions. For example, the ventilation air methane (VAM) coming from mine ventilation fans accounted for 89 billion cubic feet (bcf) of the 151 bcf of coal mine methane (CMM) emitted in the United States in the year 2000. The capture and use of VAM is problematic because of the large volumes of mine ventilation air and its low methane concentration, typically $0.3 \%$ to $1.5 \%$.

A thermal flow reversal reactor (TFRR) system (specifically, the MEGTEC VOCSIDIZER ${ }^{\mathrm{TM}}$ oxidation system) is equipment that can oxidize the dilute methane in the mine ventilation air. The equipment is self-sustaining at low methane concentrations $(0.2 \%-1.2 \%)$, without reliance on another source of combustion. The system will convert the methane to carbon dioxide and produce essentially no $\mathrm{SO}_{\mathrm{x}}$, $\mathrm{NO}_{x}$, or particulate, and only very minor quantities of $\mathrm{CO}$. Because methane has a 21times greater radiative forcing factor than carbon dioxide, this will substantially reduce the effective greenhouse gas emissions to the atmosphere. In addition, with the integration of a heat recovery system, the TFRR can be used to recover useful energy, thus avoiding the GHG emissions associated with the avoided fuel. Even though a commercial-size unit has not been applied to a U.S. coal mine, the oxidation technology is a proven system for destroying volatile organic compounds in over 600 applications around the world.

The purpose of this project is to demonstrate the operation of a full-scale commercial TFRR system on a U.S. coal mine. Three critical issues will be resolved by this demonstration: 1) A safe, effective interface between the TFRR and the mine will be designed and proven in use, 2) The ability of the TFRR to oxidize the low and variable concentrations of methane, effectively, economically, and in long-term operation, will be verified, 3) An engineering/economic evaluation of the technology as applied to both methane oxidation and to energy recovery will be conducted.

\section{EXPERIMENTAL}

The oxidization system will not be operational until the first quarter of calendar year 2005 . There is no operational data at this time. 


\section{RESULTS AND DISCUSSION}

STATUS OF COOPERATIVE AGREEMENT

As part of the contract documentation requirements, a quarterly power point presentation was submitted to the Contracting Officer's Representative (COR), Morgan H. Mosser in July 2003. Amendment M002 was made to the cooperative agreement on September 29, 2003. This amendment assigned David M. Hyman as the COR and obligated an additional $\$ 760,000$ in DOE funding for this budget period.

\section{PROGRESS ON MINE SAFETY AND HEALTH ADMINISTRATION APPROVAL} A pre-investigation meeting was held with the Mine Safety and Health Administration (MSHA) on May 21, 2003, to discuss CONSOL's 101(c) Petition for Modification of Application of Mandatory Safety Standard which had been submitted on March 21, 2003. After several additional communications with MSHA, CONSOL withdrew the petition on July 29, 2003. Negotiations with MSHA continue.

\section{PROGRESS ON ENVIRONMENTAL ASSESSMENT}

It has not been determined by DOE if an environmental assessment will be required for this project.

\section{PROGRESS ON PROCESS DESIGN}

CONSOL has tentatively selected the E1 Bleeder Fan on the Enlow Fork Mine as the site for the demonstration of the VOCSIDIZER. CONSOL has completed a finite element analysis on the optimum design for the interface between the VOCSIDIZER and the mine ventilation fan. The analysis shows that the interface design will not impact the mine ventilation fan operation. Specifications were developed for the interface and for the air compressor that will supply instrument air for the equipment.

A preliminary design for the concrete support structure for the equipment was developed. Due to the potentially weak bearing capacity of the soil at the site, the design uses caissons as supports with horizontally attached concrete beams underlying the base of the equipment. Construction specifications were developed for the concrete work.

MEGTEC Systems began the detailed engineering design as defined in their scope of work under the subcontract. Work has focused on support documentation for MSHA. MEGTEC submitted preliminary electrical diagrams showing all the safety features of the equipment. These were used in discussions with MSHA. The piping and instrumentation diagram for the process is $75 \%$ complete.

\section{STATUS OF ES\&H APPROVALS}

The delays in obtaining MSHA approval for the project will require the Plan Approval/Operating Permit from the Pennsylvania Department of Environmental Protection be extended when a new equipment operating schedule is developed for the project. 


\section{PROGRESS ON PUBLIC COMMUNICATIONS}

A paper entitled "Capture and Use of Coal Mine Ventilation Air Methane" (Attachment A) was presented at the Second Annual Conference on Carbon Sequestration in May 2003, in Alexandria, Virginia.

The same paper was accepted and published in the proceedings of the Twentieth Annual International Pittsburgh Coal Conference, September 2003. A poster illustrating this project was presented at the conference. The poster presentation garnered an Award for Honorable MentionTechnical Poster from the conference.

\section{CONCLUSION}

During the second six months of the project the following items were accomplished: 1) the detailed engineering design was started by MEGTEC Systems, 2) a pre-investigation meeting was held with MSHA to discuss the allegations in the 101(c) Petition for Modification of Application of Mandatory Safety Standard, 3) the 101(c) Petition for Modification was withdrawn in favor of alternative negotiations with MSHA, 4) detailed engineering was started by CONSOL Energy, and 5) a presentation of the work was made at the Second Annual Conference on Carbon Sequestration in May 2003 and at the Twentieth Annual International Pittsburgh Coal Conference in September 2003.

Delays in obtaining MSHA approval for the project have delayed the schedule. Once agreement is reached with MSHA, a review of the operational and economic impacts of the delay on the scope and schedule of the project work will follow. This review will include the DOE Contracting Officer's Representative, CONSOL Energy, and MEGTEC Systems.

\section{REFERENCES}

None 


\title{
ATTACHMENT A
}

Paper Presented at:

\author{
Second Annual Conference on Carbon Sequestration \\ Alexandria, Virginia \\ May 5-8, 2003
}

Twentieth Annual International Pittsburgh Coal Conference
Pittsburgh, Pennsylvania

September 15-19, 2003 


\title{
CAPTURE AND USE OF COAL MINE VENTILATION AIR METHANE
}

\author{
Deborah A. Kosmack \\ Research Engineer \\ CONSOL Energy Inc., Research \& Development \\ 4000 Brownsville Road \\ South Park, PA 15129 \\ Phone: 412-854-6592, Fax: 412-854-6613 \\ deborahkosmack@consolenergy.com \\ Richard A. Winschel \\ Director Coal Utilization \\ CONSOL Energy Inc., Research \& Development \\ 4000 Brownsville Road \\ South Park, PA 15129 \\ Phone: 412-854-6683, Fax: 412-854-6613 \\ dickwinschel@consolenergy.com \\ Kenneth P. Zak \\ Director Marketing \& Business Development \\ MEGTEC Systems \\ 830 Prosper Road \\ P.O. Box 5030 \\ De Pere, WI 54115 \\ Phone: 920-339-2797, Fax: 920-339-2784 \\ kzak@megtec.com
}

\begin{abstract}
CONSOL Energy Inc., Research \& Development, in conjunction with MEGTEC Systems and the U.S. Department of Energy, will design, build, and operate for up to 12 months a commercial-size thermal flow reversal reactor (TFRR) interfaced to a working coal mine ventilation fan to reduce emissions of methane, a powerful greenhouse gas. Coal mining, and particularly coal mine ventilation air, is a major source of anthropogenic methane emissions. Until now, it has not been reasonably possible to either reduce or use ventilation air methane (VAM) because of its large volumes and low concentrations. The TFRR will oxidize $\geq 95 \%$ of the methane in the input VAM to carbon dioxide. Three critical issues will be resolved by this demonstration: 1) A safe, effective interface between the TFRR and the mine will be designed and proven in use, 2) The ability of the TFRR to oxidize the low and variable concentrations of methane, effectively, economically, and in long-term operation, will be verified, 3) An engineering/economic evaluation of the technology as applied to both methane oxidation and to energy recovery will be conducted.
\end{abstract}




\section{Background}

One research objective of the Carbon Sequestration Program of the Department of Energy (DOE), is the "development of concepts that combine capture and storage of $\mathrm{CO}_{2}$ or other greenhouse gases, with concomitant reductions of criteria-pollutant emissions". Converting a greenhouse gas to products, including heat and power, rather than storing it, is within the research objective. Methane is the second most important non-water greenhouse gas (GHG). Coal mine methane (CMM) is one of several major sources of anthropogenic methane, accounting for about $10 \%$ of anthropogenic methane emissions in the United States. Ventilation air methane (VAM) is the single largest source of CMM. For example, VAM accounted for 89 billion cubic feet (bcf) of the 151 bcf of CMM emitted in the United States in the year 2000. The capture and use of VAM is problematic because of the low methane concentration in the mine ventilation air, typically $0.3 \%$ to $1.5 \%$.

Oxidizer technology, while never applied at U.S. coal mines, is used to treat emissions from other industrial processes. MEGTEC Systems is one of the world's largest supplier of oxidizer technology, with over 2500 installations worldwide. The specific equipment, self-sustaining at low methane concentrations $(0.2 \%-1.2 \%)$, is a thermal flow reversal reactor (TFRR) system (specifically, the MEGTEC VOCSIDIZER ${ }^{\mathrm{TM}}$ oxidation system). Only small pilot tests have been operated by MEGTEC on slip-streams $(\leq 5,000 \mathrm{cfm})$ of VAM emissions from coal mines in the U.K. and Australia. The purpose of this project is to demonstrate the operation of a full-scale commercial TFRR system on a U.S. coal mine. The system will convert the methane contained at low concentration (ca. 1\%) in VAM to carbon dioxide. Because methane has a 21 -times $^{1}$ greater radiative forcing factor than carbon dioxide, this will substantially reduce the effective greenhouse gas emissions to the atmosphere. In addition, with the integration of a heat recovery system, the TFRR can be used to recover useful energy, thus avoiding the GHG emissions associated with the avoided fuel. The TFRR technology has the potential to reduce GHG emissions at relatively low cost, with little or no emission of criteria pollutants, such as $\mathrm{SO}_{\mathrm{x}}, \mathrm{NO}_{\mathrm{x}}$, particulate, and CO.

\section{Technology Description}

The commercial-size unit of the VOCSIDIZER is a two-bed modular system that will process $60,000 \mathrm{cfm}$ of mine ventilation air. The VOCSIDIZER consists of a ceramic bed material contained in an airtight steel container resting on a sturdy steel frame, see Figure 1. Above and below the bed are air plenum chambers to provide even distribution of the inlet air. The granular ceramic bed material ensures optimum flow and temperature distribution over the bed. Electrical heating elements are placed in the bed to obtain the required start-up temperature $\left(1832^{\circ} \mathrm{F}\right.$ or $\left.1000^{\circ} \mathrm{C}\right)$. The process fan at the inlet side of the VOCSIDIZER forces the feed air via pneumatically actuated valves into the plenum and through the

\footnotetext{
${ }^{1}$ The Intergovernmental Panel on Climate Change recently updated the accepted global warming potential of
} methane to be 23 in its third assessment report, but the older value of 21 is used in this document. 
preheated bed where the air is heated to a temperature at which methane is completely oxidized. The thermal energy released during methane oxidization is recovered by the bed media as the air moves to the outlet side of the bed. The exhaust air is released to the atmosphere at a temperature higher than the incoming process air. The exact temperature will depend on the methane concentration in the mine ventilation air and the presence or absence of a heat recovery system in the bed. Thermocouples in the bed are tied to the programmable logic controller (PLC) system that monitors the temperature profile of the bed and the movement of the high temperature zone, which moves towards the outlet of the ceramic bed. To maintain the high temperature zone within the ceramic bed, large switching valves reverse the air flow through the bed periodically. The PLC program optimizes valve switching intervals using time and temperature to maximize energy efficiency. After the valves have switched and reversed the direction of air flow through the bed, the energy that was recovered and stored in one side of the bed heats the incoming process air to oxidation temperature. The high temperature zone in the bed now moves toward the new outlet and the process repeats. In operation, the VOCSIDIZER typically changes air flow direction through the bed every 120 seconds. The reaction zone at the oxidation temperature is sustained in the center of the bed by optimizing the regenerative heat exchange between the ventilation air and the ceramic bed. Figure 2 shows the reversal air flow through the bed based on valve position.

The programmable logic controller also provides logic and sequence controls, and monitors various plant/process parameters. The safety and alarm functions incorporated into the system include high and low bed temperatures, high exhaust temperatures, low compressed air pressure, high methane concentration, and mine ventilation fault. In alarm mode, the fan is shut off and the dampers are shut to isolate the unit from the mine. Because the unit has rugged construction, few moving parts, and advanced control, it is expected that the system will require little maintenance and maintain reliable emission control performance. The expected methane conversion is $95 \%$.

\section{Project Objectives}

The proposed work is designed to determine the long-term technical/economic feasibility of applying the technology in context to the safe and efficient operation of a large underground coal mine. The three key objectives that are to be accomplished by this project are to: 1) design an effective interface between the TFRR and the mine ventilation system that does not compromise mine safety, 2) convert the low and variable concentrations of methane contained in the coal mine ventilation air to carbon dioxide effectively and economically, and 3) determine the quantity of useful energy that can be economically produced when processing ventilation air from a working coal mine and perform an engineering/economic evaluation of the concept. 
The use of a commercial-size unit will allow accurate technology transfer for further applications. Careful documentation of the inputs and outputs will allow testing, analysis, and optimization of key operating parameters to achieve optimum methane conversion and heat recovery. Daily inspections and continuous data recording will assist in the performance evaluation and in determining projected operating and maintenance costs.

\section{Work Plan}

The project includes the design and permitting (as necessary) of the mine interface, detailed design of the oxidation system, procurement of the unit and auxiliary equipment, selection and preparation of an operating coal mine site, installation of the system, start-up and commissioning of equipment, operation, and data analysis. The project will last from twenty-five to twenty-nine months, beginning October 1, 2002. The construction and start up of the facility is expected to be completed nine months after the major equipment is procured. The demonstration unit will be operated for up to twelve months, during which time an experimental program will be conducted. The final three months will be used to complete the engineering/economic analysis and for reporting and dissemination of project results and conclusions.

The work is organized as seven tasks. Some tasks will be conducted simultaneously and others will be sequential. The following text outlines each task and what each is to accomplish.

Task 1.0 - Final Site Selection, Conceptual Design, and Permitting - The criteria being used to determine the ideal site location for the VOCSIDIZER are to have 1) sufficient acreage to install the equipment, 2) adequate topography to minimize site preparation, 3) an existing mine ventilation fan that will release sufficient concentration of methane, 4) site that has over $60,000 \mathrm{cfm}$ mine ventilation air. A suitable site has been identified. The fan at the site has been in operation since 1999 with an average flow rate of $210,000 \mathrm{cfm}$. The methane concentration has ranged from $0.9 \%$ to $1.5 \%$ in 2002 . It is located outside of the active underground mining area, which will reduce the potential dust particles in the air stream. The Mine Safety and Health Administration (MSHA) has ruled that the new installation will be under their jurisdiction on the surface of the coal mine. Therefore, the design for the oxidation system and mine/oxidizer interface must be acceptable to MSHA. A 101(c) Petition for Modification has been submitted to MSHA for design approval of the VOCSIDIZER. The requirements for state and local air, water, and noise emission permits, local building permits, and revisions to the existing Surface Mine Control and Reclamation Act permit are being evaluated. A request and exemption have been obtained from the Pennsylvania Department of Environmental Protection from the Plan Approval/Operating Permit requirements under $25 \mathrm{PA}$ Code $\S 127.14(8)$. Appropriate requests for permits will be submitted to the regulating authorities as needed. 
Task 2.0 - Preparation of Environmental Assessment Report (Optional) - Based on the characteristics of the site selected by CONSOL and resulting permit requirements, preparations of an Environmental Assessment (EA) that complies with both the National Environmental Policy Act (NEPA), as specified in 10 CFR 600 Part 1021, and the DOE recommendations for NEPA document preparation. If DOE makes a determination that an EA is required, CONSOL shall provide the descriptive project details and related environmental characterizations and analysis necessary to support preparation of NEPA documentation that complies with the cited requirements.

Task 3.0 - Detailed Design - A detailed design, including a defined control scheme, will be produced on the basis of Task 1. The detailed design will include a piping \& instrumentation drawing of the process, equipment plans with duct work and piping, and structural drawings specific to the site. The major subcontract with MEGTEC Systems has been signed, which allows the detailed design to be started.

Task 4.0 - Procurement and Construction - MEGTEC will provide the VOCSIDIZER 2x2315-250FDHT system, the control cabinet, and fan with inverter drive unit on the basis of the Task 3 detailed design. On-site construction and installation will begin six months after procurement of the major equipment.

Task 5.0 - Startup and Commissioning - Startup and commissioning will be accomplished by team members from MEGTEC and CONSOL. All safety and operating systems and all monitoring and data logging equipment will be tested for proper function.

Task 6.0 - Operation - Day-to-day operation will be CONSOL's responsibility, although MEGTEC will provide routine testing and maintenance throughout the demonstration period. Daily checks of the system will be made at the site by a mine operator, monthly visits will be made by engineers to download data and check equipment, and quarterly visits will be made by engineers for maintenance. Air emission testing will be performed three times to verify the performance of the unit. A two-level, two-variable experimental design will be conducted to statistically determine the effects of the independent variables (mine ventilation air flow rate and VAM concentration) on the response of the TFRR bed temperature and methane conversion to evaluate the potential production and recovery of energy from the system. Throughout the course of the operating period (up to 12 months), the pressure drop across the TFRR bed will be monitored to examine any long-term increases caused by dust accumulation.

Task 7.0 - Documentation - Operation will be followed by documentation, analysis, and evaluation of key operating parameters, process performance, and operating and maintenance issues. An engineering/economic evaluation will be conducted for a conceptual large commercial-size $(180,000 \mathrm{cfm})$ system equipped with an energy recovery system. 


\section{Future Opportunities}

This technology, if successfully demonstrated, can provide new opportunities to reduce greenhouse gas emissions by the reduction of ventilation air methane emissions from coal mines. A large commercialsize installation $(180,000 \mathrm{cfm})$ of TFRR technology on a single typical mine ventilation bleeder fan would reduce methane emissions by 14,200 to 23,700 ton per year (the equivalent of 260,000 to 430,000 ton carbon dioxide). The heat recovered from the oxidation process may be utilized directly or for electricity generation. This would reduce the demand on fossil fuel generating stations, thus reducing the emissions of $\mathrm{SO}_{2}, \mathrm{NO}_{\mathrm{X}}, \mathrm{CO}$, and other criteria pollutants. A single commercial TFRR installed on a typical mine bleeder fan unit could produce 4.7-7.7 MW of electricity or 18-30 MW of thermal energy. The demonstration program will result in the generation of more reliable capital, operating, and maintenance cost information; this will substantially reduce the economic uncertainty associated with future installations.

\section{Acknowledgements}

This paper was prepared with the support of the U.S. Department of Energy, under Award No. DE-FC2602NT41620. However, any opinions, findings, conclusions, or recommendations expressed herein are those of the authors and do not necessarily reflect the views of the DOE. Other contributors to this project are CONSOL Energy Inc. and MEGTEC Systems.

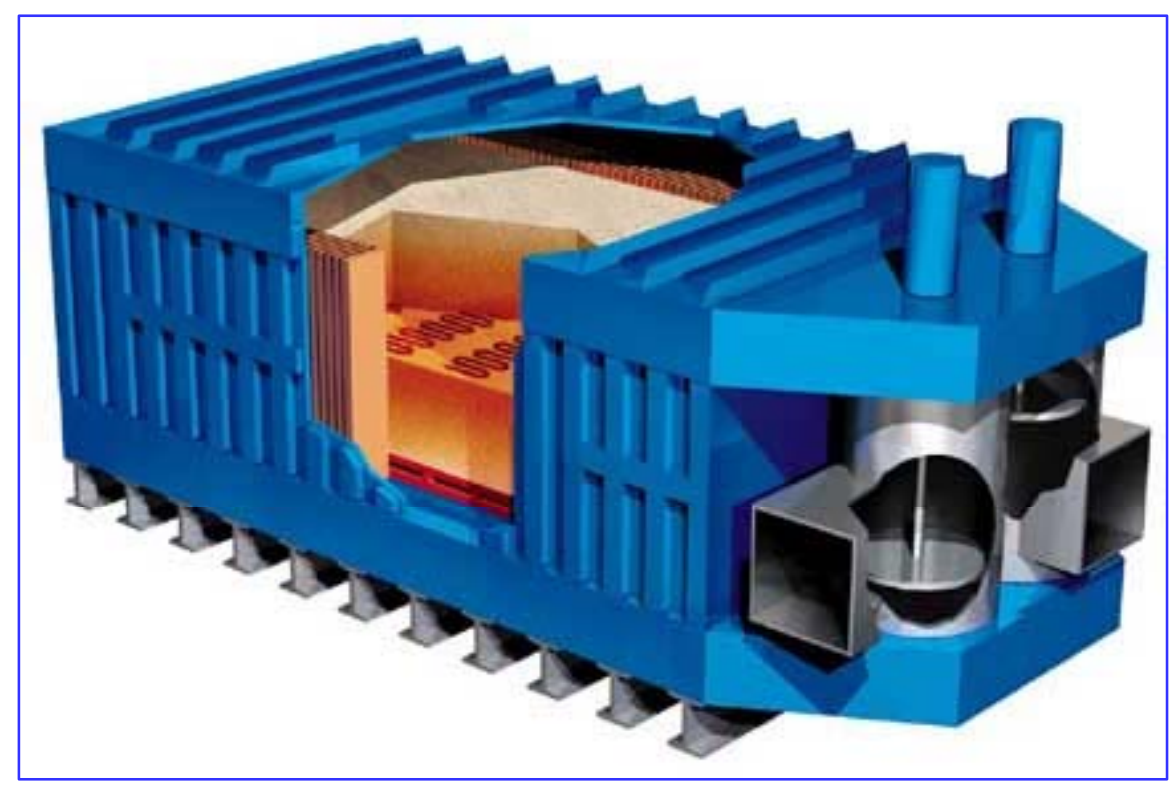

Figure 1: Internal View of VOCSIDIZER -

Visible are heating coil, insulation, switching valves, and air plenum 


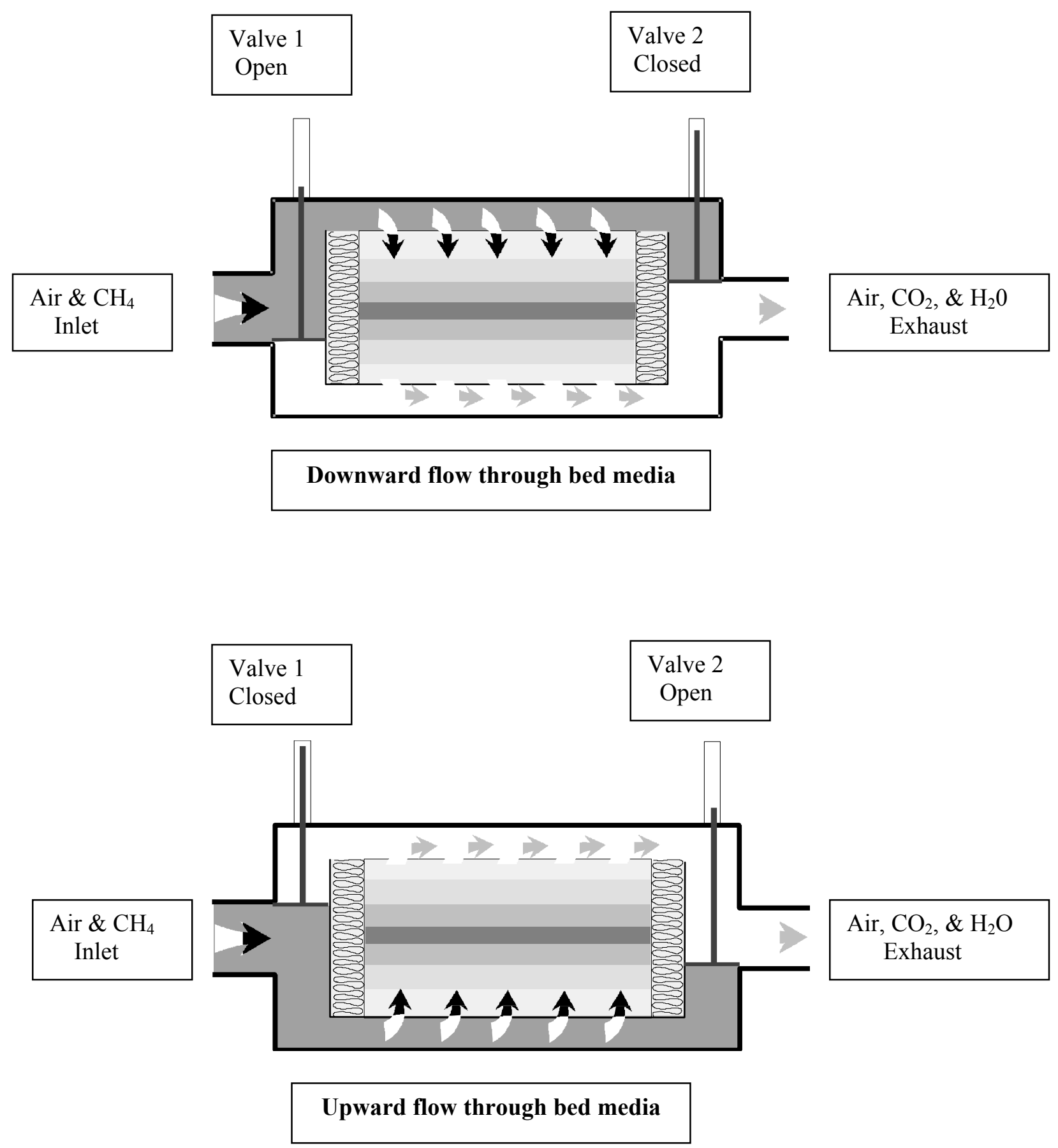

Figure 2. Cyclic Air Flow in Thermal Flow-Reversal Reactor 